\title{
Intrasellar Meningioma Mimicking Pituitary Adenoma: (Case Report)
}

\author{
Lakhdar .F ${ }^{1}$, Louraoui .M², Maaqili . $\mathbf{R}^{3}$, El Abbadi . $\mathbf{N}^{4}$ \\ M.D, PhD, Neuro Surgeon at Ibn Sina hospital Rabat, Morocco \\ M.D, Neuro Surgeon at Ibn Sina hospital, Rabat, Morocco \\ Professor, Neuro Surgery at Ibn Sina hospital of Rabat, Morocco
}

M.D, PhD, Professor and Chief of Department of Neuro Surgery at Ibn Sina Hospital, Rabat, Morocco

\begin{abstract}
Intrasellarmeningiomas are rare tumors that have the ability to mimic non-functioning pituitary adenomas. The authors report a 65-year-old man with complaints of intermittent pulsatile headache for 6 months and visual disturbance. A magnetic resonance image (MRI) showed a large heterogeneously enhanced intrasellar mass lesion, occupying hypophyseal fossa. The patient underwent microscopic transsphenoidal surgery for removal of the tumor. Microscopic examination and immunohistochemical staining of the tumor specimen was performed and confirmed the diagnosis of meningioma. The authors emphasize that careful evaluations of MR imaging will allow the correct preoperative diagnosis in patients with intrasellar meningioma mimicking pituitary macroadenoma.
\end{abstract}

Keywords: Pituitary Adenoma, intrasellar meningioma, sellarturcica, differential diagnosis

\section{Introduction}

Although meningioma often occurs in parasellar regions such as the tuberculum sellae, olfactory groove, and sphenoid wing, pure intrasellarmeningiomas are extremely rare.

Generally,meningiomas are slowly progressive and are not typically associated with a sudden onset of symptoms such as headache and visual trouble.It is difficult to differentiate intrasellarmeningiomas from pituitary tumors. Correct preoperative diagnosis depends on clinical picture, neuroimaging and endocrine studies.

\section{Case Report}

A-65-year-old man described a 6-month history of a persistent bilateralparieto-occipital headache, combined with a few weeks of vomiting,reduced visual acuity and visual field defect. Physical examination found Visual acuity 0.6 in the right eye and 0.5 in the left eye with bitemporalhemianopsia. No other abnormal signs were observed.

A magnetic resonance imaging (MRI) scan revealed a $1.8 \times 1.9 \times 2.2 \mathrm{~cm}$, enhanced heterogeneousintrasellar mass withsuprasellar extension, the optic chiasm was slightly displaced,and the sellaturcica showed enlargement with intrasellar calcification(Fig. 2). Hormone tests prior to surgical intervention revealed decreased levels of triiodothyronine (T3) ( $1 \mathrm{nmol} / 1$; normal range, 1.30-3.30 $\mathrm{nmol} / \mathrm{l}$ ) and free T3 (1.96 pmol/1; normal range, 3.2-7 $\mathrm{pmol} / \mathrm{l})$. Other hormone levels were all normal.Preoperative diagnosis was pituitary adenoma.

The tumor was subtotally removed by using the transsphenoidal approach. The sella floor and dura matter were intact. The grey, soft and necrotic tumor tissue was encountered and bleeding was controllable. The tumor extending to suprasellar region was firm in consistency. Microscopic examination of the tumor specimen was performed,with hematoxylin and eosin (H\&E) staining,and immunhistochemical staining confirmed a diagnosis of typical meningothelial meningioma (grade I WHO).

Following surgery, the patient headache was alleviated, visual field defect improved and visual acuity was recovered immediately.

\section{Discussion}

Meningiomas account for $34.7 \%$ of all primary intracranial tumors observed in adults, the majority of which are benign (1). However, these tumors rarely develop at the intrasellar region. Chief complaints or symptoms, in almost all cases, were visual disturbance, visual field defect, general fatigue, and disturbance of consciousness caused by compression of the optic nerve or the pituitary gland (hypopituitarism)(1).

Intrasellar meningioma and pituitary adenoma share comparable features on CT and MRI scans. Enlargement of the sellarturcica is frequently observed, but an hourglass appearance is rare among intrasellarmeningiomas(2). CT and MRI scans may reveal a well-enhanced intrasellar or intrasuprasellar mass that is difficult to distinguish from pituitary adenoma, or even pituitary apoplexy $(3,4)$. Dural enhancement, including the tail sign, is not specific, as it is one of the most common manifestations of meningioma. However, a differential diagnosis may still be conducted efficiently the majority of the time.

The dura mater provides a close lining to the floor of the sella and laterally participates in the formation of the internal wall of the cavernous sinus, then of the diaphragmasellae. The dura mater of the sellaturcica has a relatively large surface; It is possible that a meningioma may originate from the floor or the posterior wall of the sellaturcica. The so-called meningeal "tail sign"seems to be 


\section{International Journal of Science and Research (IJSR) \\ ISSN (Online): 2319-7064}

Index Copernicus Value (2013): 6.14 | Impact Factor (2015): 6.391

one of the very important MRI findings in the differential diagnosis for pituitary adenomas(4).

Kinjo and Al-Mefty et al.(5) divide diaphragmasellaemeningiomas into three types according to their site of origin: Type A originates from the upper leaf of the diaphragmasellae anterior to the pituitary stalk; Type B originates from the upper leaf of the diaphragmasellae posterior to the pituitary stalk; and Type $\mathrm{C}$ originates from the inferior leaf of the diaphragmasellae (intrasellar meningioma). Although they state that Type $\mathrm{C}$ corresponds to intrasellarmeningiomas, it is unthinkable that our case originated from the inferior leaf of the diaphragmasellae, because the neuroradiologic and operative findings in our case suggest that this meningioma originated from the floor of the sellaturcica, and extended upward and posteriorly to the dorsum sellae.

It is important to differentiate a diaphragm sellaemeningioma from a pituitary macroadenoma because they require different surgical approaches. Cappabianca et al. (5) emphasized that, most of the intra- and suprasellarmacroadenomas could be approached by the transsphenoidalroute, while diaphragmasellaemeningiomas might require a craniotomy. For diaphragmasellaemeningiomas, the cranio-orbital approach for type A and type B meningiomas, whilethe transcranialtranssphenoidal approach is preferred for a type $\mathrm{C}$ meningioma(6).Although, for all subdiaphragmaticmeningiomasthe transsphenoidal approach is advocated(9), or should be tried first, irrespective of whether the lesion is a meningioma or a pituitary adenoma.On the other hand, We hypothesize that the transsphenoidal approach should be considered to provide a moderately safe route to an intrasellar mass (even with small suprasellar extension), regardless of the pathological nature of the lesion. However, in others cases, it may not be the leading choice for intrasellarmeningiomas, as the tumor may be too firm and solid to be extirpated, and difficult to control the hemorrhage, which requires reoperation via transcranial approach $(7,8)$. The combined transsphenoidal and transcranial approach could be applied for large intra-suprasellar masses to remove the tumor completely with good control of hemorrhage.

\section{Conclusion}

Intrasellarmeningiomas are rare, which are easily confused with pituitary macroadenomas. In clinical, radiological examination and endocrinological findings, there is no definite difference between pituitary adenoma and intrasellar meningioma.Surgically, the transsphenoidal approach provides a relatively safe route to the intrasellarmeningiomas with satisfactory results.
- Ethics approval and consent to participate: Not applicable in this section

-Consent for publication: the authors have consent from the patient to publish

-No competing interests

-Authors' contributions: All the authors have contributed to the manuscript (surgery, scientific research...

\section{References}

[1] Sathananthan M, Sathananthan A, Scheithauer BW, Giannini C, Meyer FB, Atkinson JL, Erickson D.Sellarmeningiomas: an endocrinologic perspective. Pituitary. 2013 Jun;16(2):182-8.

[2] MJ, Weintraub J.Suprasellar meningioma with intrasellar extension simulating pituitary adenoma. Case report.Arch Ophthalmol. 1987 Nov;105(11):1488-9.

[3] Satoh H1, Arita K, Kurisu K, Sumida M, Nakahara T, Eguchi K, Kuroki K.Intrasellar meningioma: characteristic imaging findings.Neuroradiology. 1996 May;38(4):328-9.

[4] Michael AS1, Paige ML.MR imaging of intrasellarmeningiomas simulating pituitary adenomas. J Comput Assist Tomogr. 1988 Nov-Dec;12(6):944-6.

[5] Cappabianca P, Cirillo S, Alfieri A, D’Amico A, Maiuri F, Mariniello G, et al. Pituitary macroadenoma and diaphragm sellae meningioma: differential diagnosis on MRI. Neuroradiology 1999;41:22-26

[6] Seung Woo Cha, Dong Woo Park, Choong-ki Park, Young-Jun Lee, Seung Ro Lee, JuYeonPyo.Pure Intrasellar Meningioma Located Under the Pituitary Gland: Case Report. Korean J Radiol 2013;14(2):321323.

[7] Grisoli F, Vincentelli F, Raybaud C, Harter M, Guibout M, Baldini M.Intrasellar meningioma. Surg Neurol. 1983 Jul;20(1):36-41.

[8] Peizhi Zhou, Senlin Yin, Shu Jiang, Bowen Cai. Oncology letter11: 1073-1076, 2016. Malignant intrasellar meningioma presenting as an invasive pituitary macroadenoma: A rare case report and literature review.

[9] Honegger J1, Fahlbusch R, Buchfelder M, Huk WJ, Thierauf P.The role of transsphenoidalmicrosurgery in the management of sellar and parasellar meningioma.Surg Neurol. 1993 Jan;39(1):18-24. 
International Journal of Science and Research (IJSR)

ISSN (Online): 2319-7064

Index Copernicus Value (2013): 6.14 | Impact Factor (2015): 6.391
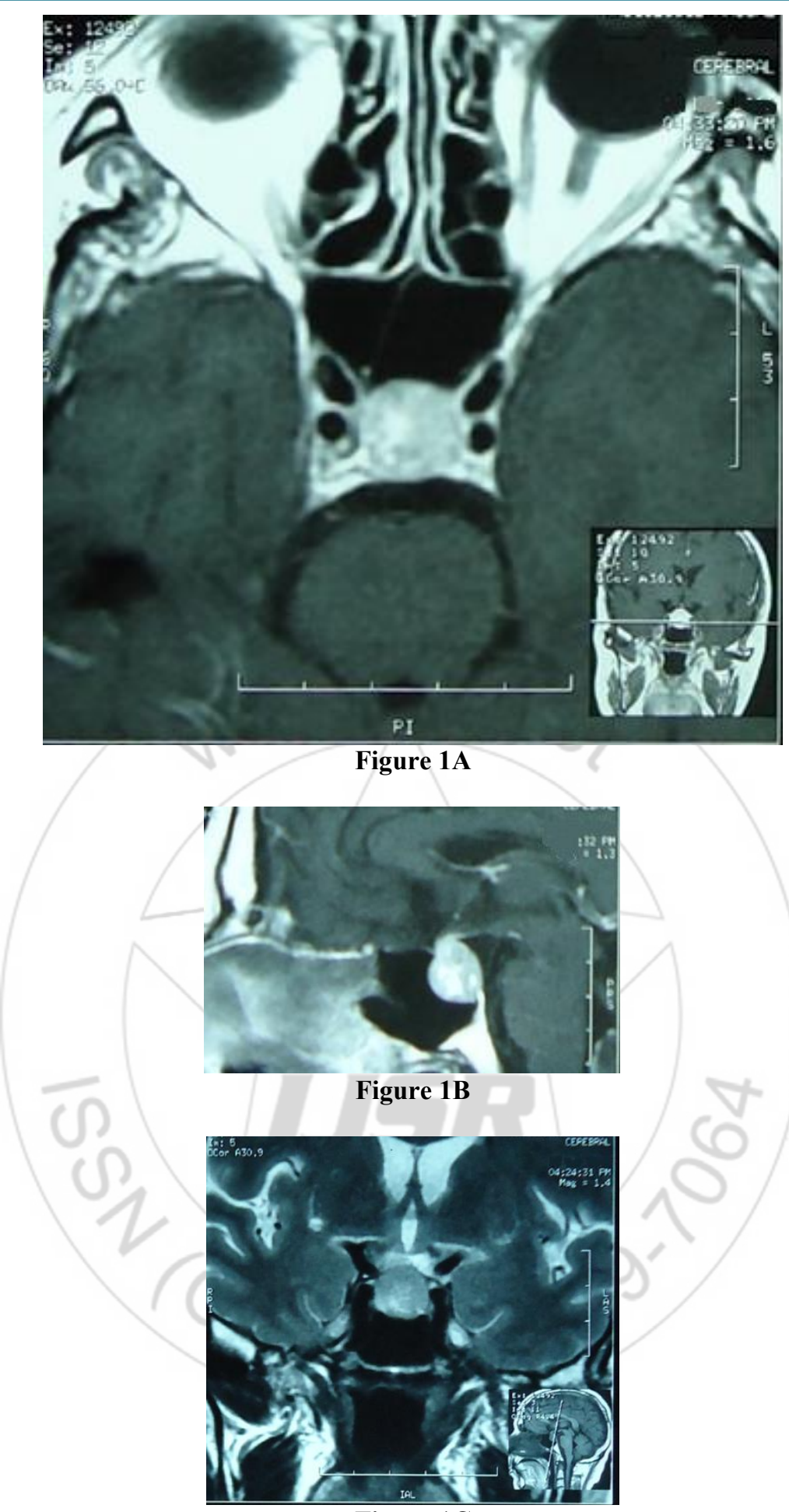

Figure 1C

Figure 1: Axial (A), and sagittal (B) T1-weighted MRI images and coronal T2 (C) weighted MRI showing a well-enhanced intrasuprasellar mass with several flow-void signs. 